\title{
Vitamin D and Geriatric syndromes: Possible links
}

\author{
Samia A Abdul-Rahman, M.D.* \\ *Geriatric and Gerontology department, Ain Shams University, Cairo, Egypt.
}

Background: Vitamin D deficiency is a very common problem among elderly population. Extra-skeletal functions of vitamin D are an interesting new area of research since the discovery of vitamin D receptors in different extra-skeletal organs and possible links to common geriatric syndromes and problems have been examined. This presentation reviews current knowledge regarding vitamin D possible links to common geriatric syndromes.

\section{Introduction:}

Since the autocrine/paracrine functions of vitamin $\mathrm{D}$ are becoming increasingly widely recognized with several organs possessing the enzymatic machinery to convert 25 hydroxyvitamin $\mathrm{D}[25(\mathrm{OH}) \mathrm{D}]$, to the active form, 1,25dihydroxyvitamin $\quad \mathrm{D}$ $[1,25(\mathrm{OH}) \mathrm{D}]$, has provided new insights into the function of this vitamin ${ }^{(1-2)}$.

Among other tissues; prostate, breast, colon, brain, and immune cells are the most known tissues that possess vitamin D receptors ${ }^{(1)}$. Not only that its receptors are in many tissues but also it controls the function of over 200 genes, including genes responsible for the regulation of cellular proliferation, differentiation, apoptosis, and angiogenesis (3).

Although there is no consensus on optimal levels of $25(\mathrm{OH}) \mathrm{D}$ as measured in serum, vitamin $\mathrm{D}$ deficiency is defined by most experts as a $25(\mathrm{OH}) \mathrm{D}$ level of less than 20 $\mathrm{ng} / \mathrm{ml}{ }^{(4)}$. Vitamin D deficiency is very common especially among elderly populations with reports of prevalence as high as $84 \%$ in some countries ${ }^{(5)}$.

Since prevalence is even higher among elderly with comorbidities it is very possible that vitamin $\mathrm{D}$ could be associated with common geriatric syndromes.
Geriatric syndromes possibly linked to vitamin D deficiency:

Frailty:

$25(\mathrm{OH}) \mathrm{D}$ deficiency is associated with debilitating chronic diseases and age-related conditions that may influence physical functioning and hence relation to frailty was considered in research ${ }^{(7)}$.

The largest of these studies was that of Wilhelm-Leen and coleagues (2010). Using data from the Third National Health and Nutrition Survey (NHANES III), 25(OH) D deficiency, defined as a serum concentration $<15 \mathrm{ng} / \mathrm{mL}$ ), was associated with a 3.7-fold increase in the odds of frailty amongst whites and a four-fold increase in the odds of frailty amongst non-whites ${ }^{(7)}$.

Also, a cross-sectional study on a total of 1,504 community-dwelling men aged 60-79 years- using multinomial logistic regressionfound lower levels of $25(\mathrm{OH}) \mathrm{D}$ were associated with being pre-frail and frail even after adjustment for confounders. Among the five frailty phenotypes (FP) criteria, only sarcopenia was not associated with 25(OH)D levels ${ }^{(8)}$.

Association was low muscle mass was examined again in the cross-sectional study of Dupuy and colleagues using data from the EPIDOS study. The results again showed 
that no association between low muscle mass and low dietary intakes of vitamin D (9)

Longitudinal studies are needed to examine if vitamin $\mathrm{D}$ supplementation to vitamin $\mathrm{D}$ deficient frail persons with sarcopenia has any effect on either frailty status or muscle mass.

\section{Incontinence and pelvic floor dysfunction:}

Urinary continence requires coordinated muscle function with relaxation of the bladder detrusor allowing the bladder to fill, followed by detrusor contraction with concomitant sphincter relaxation at a time controlled by the individual. Since bladder musculature possesses vitamin D receptors and responds to vitamin $\mathrm{D}$ analogues, vitamin D deficiency perhaps could influence bladder dysfunction ${ }^{(10-11)}$.

Pelvic floor dysfunction in females is common, and its prevalence increases with age. The prevalence of urinary incontinence (UI) varies by definition but has been reported to range between $13 \%$ and $49 \%{ }^{(12-}$ 16).

A relation between osteoporosis and pelvic floor muscles function was suggested in research (17) and so the idea to study its relation to vitamin D deficiency only seems rational.

Prospective cohort or randomized studies investigating the relationship between vitamin D nutritional status and pelvic floor disorders symptoms are lacking but observational studies show a possible link. One study including more than 1800 adult women showed that as many as $82 \%$ of the participants had low levels of vitamin D. However those who had pelvic floor disorders and/or incontinence had levels significantly lower than those of the rest of the group ${ }^{(18)}$.

Links to fecal incontinence have been examined in a small cohort study of patients with fecal incontinence, it was shown that all patients had hypovitaminosis D $(60 \%$ had vitamin deficiency and $40 \%$ with relative vitamin $\mathrm{D}$ insufficiency). The mean vitamin D level in patients with fecal incontinence was $17 \mathrm{ng} / \mathrm{ml}$ (range 5.4-22.2 ng $/ \mathrm{ml}$ ) with a significantly higher prevalence than the general population ${ }^{(19)}$.

Longitudinal studies are still lacking but two case studies are available; the first was a 78year-old woman with symptoms of urge incontinence who had vitamin $\mathrm{D}$ deficiency [25(OH)D <10 ng/ml] who claims her UI resolved with vitamin $\mathrm{D}$ supplementation. The second reported case was a 59-year-old woman with stress urinary incontinence symptoms who had a $25(\mathrm{OH}) \mathrm{D}$ level of 13 $\mathrm{ng} / \mathrm{ml}$. However, these symptoms resolved even before normalization of her serum vitamin D level $^{(20)}$.

\section{Dementia and cognitive impairment:}

It has only been in the last decade or so that vitamin $\mathrm{D}$ has been thought to function as a neuro-steroid ${ }^{(21)}$ and research yielded a large amount of knowledge regarding vitamin $\mathrm{D}$ and its previously unknown role in brain development and function. For example, the distribution of the vitamin $\mathrm{D}$ receptor (VDR) and the enzyme associated with the synthesis of the active form of the hormone $1 \alpha$-hydroxylase (CYP27B1) has been mapped in human brain ${ }^{(22)}$.

Hypovitaminosis D has been associated with cognitive decline in the elderly, Parkinson's disease and Alzheimer's disease ${ }^{(23-26)}$. In a large prospective study of cognitive decline, aging and 25OHD3, cognitive decline and the rate of decline were increased in subjects 
severely deficient in 25OHD3 $(<25 \mathrm{nM})^{(25)}$. However, it is unclear if associations between hypovitaminosis $\mathrm{D}$ and psychiatric disorders are causative or circumstantial, but there is some evidence for symptom improvements with vitamin D supplementation ${ }^{(24)}$.

Recently, in a cross-sectional and longitudinal analysis of a prospective cohort of 6,257 community-dwelling elderly women followed for 4 years, a lower serum $25(\mathrm{OH}) \mathrm{D}$ level at baseline predicates cognitive decline during the 4.6 years follow-up ${ }^{(27)}$.

Another follow-up study on 498 community-dwelling elderly females found that low baseline vitamin D level, as well as low vitamin D intake was predictors of Alzheimer's dementia but not other types of dementia $^{(28)}$.

\section{Depression:}

Vitamin D has also been linked to depression which is one of the most common mental disorders in elderly populations. Stumpf and colleagues first suggested that vitamin D may contribute to the higher prevalence of seasonal affective disorders at high latitudes ${ }^{(29)}$. However to date, the results of small trials of vitamin D supplements in seasonal affective disorder have been inconclusive ${ }^{(30-32)}$.

Even with large cross-sectional studies the results are conflicting. A number of crosssection studies have reported association between low vitamin D and depression (3335). While other cross-sectional studies have failed to find such an association when controlled for potential confounding factors (36-38).

The influence of potential confounds has been examined in a larger observational study from Europe on 1283 community- dwelling elderly (65-95 years), it was reported that those with lower $25(\mathrm{OH}) \mathrm{D}$ levels were at significantly increased risk of both minor and major depression. The severity of symptoms was significantly associated with decreased serum $25(\mathrm{OH}) \mathrm{D}$ levels and increased serum PTH levels ${ }^{(39)}$.

Another large, population-based survey of the elderly $(n=2070$ participants, aged 65 years and older) reported a significant increased risk of depressive symptoms in those with vitamin D deficiency ${ }^{(40)}$.

A 6-year prospective study of 954 adults aged 65 years and older examined the association between low vitamin $\mathrm{D}$ at baseline and subsequent (incident) depression ${ }^{(41)}$. Those with $25(\mathrm{OH}) \mathrm{D}$ less than $50 \mathrm{nM}$ at baseline (compared with those with higher levels) experienced significantly higher scores on measures of depression at 3 and 6 year follow-up. The study was able to adjust for a range of potential confounds, and examined the association between the variables of interest in a prospective fashion, thus lending weight to the hypothesis that low vitamin $\mathrm{D}$ may contribute causally to depression. A reanalysis of the Women's Health Initiative examined the association between dietary vitamin $D$ intake at baseline in a very large sample $(\mathrm{n}=81,189)$. Those with the highest dietary intake has lower scores on depressive symptoms at the 3 year followup, and this finding persisted after adjustments for a range of potential confounding factors ${ }^{(42)}$.

Recommended doses of vitamin D supplementation:

Vitamin D supplementation intake recommendations are controversial based upon the targeted condition. To address the debate over how much vitamin $D$ supplementation to recommend, the Institute 
of Medicine (IOM) published the 2011 report on dietary reference intakes for vitamin D to be $600 \mathrm{IU} /$ day for ages 1 to 70 years, and $800 \mathrm{IU} /$ day for those older than 71 years in musculoskeletal conditions ${ }^{(43)}$. Nevertheless, there is ample evidence that vitamin $\mathrm{D}$ doses above these recommendations are well tolerated ${ }^{(44-45)}$.

Yet; due to the lack of conclusive level I evidence, the IOM concluded that recommendations for vitamin $\mathrm{D}$ supplementation to address any other condition-specific goal must await larger epidemiologic or randomized studies ${ }^{(43)}$.

\section{Screening potential:}

Several problems are inevitably connected with the use of plasma $25(\mathrm{OH}) \mathrm{D}$ to assess vitamin $\mathrm{D}$ status. One important problem is that plasma $25(\mathrm{OH}) \mathrm{D}$ level depends on unchangeable ecological factors (season, local weather conditions and latitude), modifiable individual lifestyle factors (clothing, dietary habits, etc.), and unmodifiable individual factors (race, pigmentation, skin thickness and age) (46). So, most guidelines for elderly population recommend vitamin $\mathrm{D}$ and calcium supplementation for the elderly without previous testing of vitamin D status ${ }^{(43)}$.

Future studies of feasibility of testing vitamin D status in risk groups are therefore mandated.

\section{References:}

1. Holick MF. Vitamin D: Importance in the prevention of cancers, type 1 diabetes, heart disease and osteoporosis. Am J Clin Nutr. 2004; 79:362-371,.

2. Liu PT, Stenger S, Li H, et al. Toll-like receptor triggering of a vitamin $\mathrm{D}$ mediated human antimicrobial response. Science.2006; 311:170-173.
3. Iida-Klein A, Guo J, Xie LY, et al. Truncation of the carboxyl-terminal region of the rat parathyroid hormone $(\mathrm{PTH}) / \mathrm{PTH}$-related peptide receptor enhances PTH stimulation of adenylyl cyclase but not phospholipase C. J Biol Chem.1995; 270: 8458-8465.

4. Holick MF. High prevalence of vitamin D inadequacy and implications for health. Mayo Clin Proc.2006; 81:35373.

5. Scharla SH. Prevalence of Subclinical Vitamin D Deficiency in Different European Countries. Osteoporos Int.1998; Suppl. (8):S7-S12.

6. Chang CI, Chan DC, Kuo KN, Hsiung CA, Chen C. Vitamin D insufficiency and frailty syndrome in older adults living in a Northern Taiwan community. Archives of Gerontology and Geriatrics.2010; 50(Supplement 1): S17S21.

7. Wilhelm-Leen ER, Hall YN, deBoer IH, Chertow GM. Vitamin D deficiency and frailty in older Americans. J Intern Med.2010; 268: 171-180.

8. Fried LP, Tangen CM, Walston $\mathrm{J}$, et al. Cardiovascular Health Study Collaborative Research Group. Frailty in older adults: evidence for a phenotype. J Gerontol A Biol Sci Med Sci.2001; 56(3):M146-56.

9. Dupuy C, Lauwers-Cances V, Kan VAV, et al. Dietary vitamin D intake and muscle mass in older women. Results from a cross-sectional analysis of the EPIDOS study. The journal of nutrition, health \& aging.2013; 17(2): 119-124.

10. Crescioli C, Morelli A, Adorini L, et al. Human bladder as a novel target for vitamin $\mathrm{D}$ receptor ligands. J Clin Endocrinol Metab.2005; 90:962-972. 
11. Schroder A, Colli E, Maggi M, Andersson KE. Effects of a vitamin D3 analogue in a rat model of bladder outlet obstruction. BJU Int.2006; 98:637-642.

12. Nygaard I, Barber MD, Burgio KL, et al. Prevalence of symptomatic pelvic floor disorders in US women. JAMA.2008; $300 \quad$ (11):1311-1316, 2008.

13. Sung VW, Hampton BS. Epidemiology of pelvic floor dysfunction. Obstet Gynecol Clin N Am.2009; 36:421-443.

14. Melville JL, Katon W, Delaney K, et al. Urinary incontinence in US women: a population-based study. Arch Intern Med.2005; 165(5): 537-542.

15. Dooley Y, Kenton K, Cao G, et al. Urinary incontinence prevalence: results from the National Health and Nutritional Examination Survey. J Urol. 2009; 179(2):656-661.

16. Irwin DE, Milsom I, Hunskaar S et al. Population-based survey of urinary incontinence, overactive bladder, and other lower urinary tract symptoms in five countries: results of the EPIC study. Eur Urol.2006; 50(6):1306-1314.

17. Holick MF, Chen TC, Lu Z, Sauter E. Vitamin D and skin physiology: a Dlightful story. J Bone Miner Res.2007; 22(suppl 2):V28-33.

18. Badalian SS, Rosenbaum PF. Vitamin D and pelvic floor disorders in women: results from the National Health and Nutrition Examination Survey. Obstet Gynecol.2010; 115(4):795-803.

19. Alkhatib AA, Tuteja AK. High Prevalence of Vitamin D Deficiency among Patients with Fecal Incontinence. Dig Dis Sci.2010; 55:3632-3633.

20. Gau ET. Urinary incontinence resolved after adequate vitamin D supplementation: a report of two cases. JAGS. 2010; 58(12):2438-2439

21. Harms LR, Burne THJ, Eyles DW, McGrath JJ. Vitamin D and the brain. Best Practice \& Research Clinical Endocrinology \& Metabolism.2011; 25: 657-669.

22. Eyles DW, Smith S, Kinobe R, et al. Distribution of the vitamin $\mathrm{D}$ receptor and 1 alpha-hydroxylase in human brain. Journal of Chemical Neuroanatomy.2005, 29: 21-30.

23. Evatt ML, DeLong MR, Khazai N, et al. Prevalence of vitamin D insufficiency in patients with Parkinson disease and Alzheimer disease. Archives of Neurology.2008; 65: 1348-1352.

24. Jorde R, Sneve M, Figenschau Y et al. Effects of vitamin D supplementation on symptoms of depression in overweight and obese subjects: randomized double blind trial. Journal of Internal Medicine .2008; 264: 599-609.

25. Llewellyn DJ, Lang IA, Langa KM, et al. Vitamin D and risk of cognitive decline in elderly persons. Archives of Internal Medicine. 2010; 170: 11351141.

26. May HT, Bair TL, Lappe DL, et al. Association of vitamin D levels with incident depression among a general cardiovascular population. American Heart Journal.2010; 159: 1037-1043.

27. Slinin Y, Paudel M, Taylor BC, et al. Association Between Serum 25(OH) Vitamin D and the Risk of Cognitive Decline in Older Women. J Gerontol A Biol Sci Med Sci. 2012 ; 67 (10): 10921098.

28. Annweiler C, Rolland Y, Schott AM, et al. Higher Vitamin D Dietary Intake Is Associated With Lower Risk of Alzheimer's Disease: A 7-Year Followup. J Gerontol A Biol Sci Med Sci. 2012; 67 (11): 1205-1211.

29. Stumpf, W.E., Privette, T.H. Light, vitamin D and psychiatry. Role of 1,25 dihydroxyvitamin D3 (soltriol) in etiology and therapy of seasonal affective disorder and other mental 


\section{Egyptian Journal of Geriatrics and Gerontology March 2014 Volume 1(1)}

processes. Psychopharmacology (Berlin). 1989; 97, 285-294.

30. Gloth 3rd, F.M., Alam, W., Hollis, B. Vitamin $D$ vs broad spectrum phototherapy in the treatment of seasonal affective disorder. J. Nutr. Health Aging. 1999. 3, 5-7.

31. Lansdowne, A.T., Provost, S.C. Vitamin D3 enhances mood in healthy subjects during winter. Psychopharmacology (Berlin).1998; 135, 319-323.

32. Partonen, T., Vakkuri, O., LambergAllardt, C., Lonnqvist, J. Effects of bright light on sleepiness, melatonin, and 25-hydroxyvitamin D (3) in winter seasonal affective disorder. Biol. Psychiatry.1996; 39, 865-872.

33. Hoang, M.T., Defina, L.F., Willis, B.L., Leonard, D.S., Weiner, M.F., Brown, E.S. Association between low serum 25hydroxyvitamin $\mathrm{D}$ and depression in a large sample of healthy adults: the Cooper Center longitudinal study. Mayo Clin. Proc. 2011; 86, 1050-1055.

34. Jorde, R., Waterloo, K., Saleh, F., Haug, E., Svartberg, J. Neuropsychological function in relation to serum parathyroid hormone and serum 25- hydroxyvitamin D levels : the Tromso study. J. Neurol. 2006; 253, 464-470.

35. Wilkins, C.H., Sheline, Y.I., Roe, C.M., Birge, S.J., Morris, J.C. Vitamin D deficiency is associated with low mood and worse cognitive performance in older adults. Am. J. Geriatr. Psychiatry. 2006; 14, 1032-1040.

36. Pan, A., Lu, L., Franco, O.H., Yu, Z., Li, H., Lin, X., 2009. Association between depressive symptoms and 25hydroxyvitamin $\mathrm{D}$ in middle-aged and elderly Chinese. J. Affect. Disord. 118, 240-243.

37. Nanri, A., Mizoue, T., Matsushita, Y., Poudel-Tandukar, K., Sato, M., Ohta, M., Mishima, N. Association between serum 25-hydroxyvitamin D and depressive symptoms in Japanese: analysis by survey season. Eur. J. Clin. Nutr. . 2009; 63, 1444-1447.
38. Zhao, G., Ford, E.S., Li, C., Balluz, L.S. No associations between serum concentrations of 25-hydroxyvitamin D and parathyroid hormone and depression among US adults. Brit. J. Nutr. 2010; 104, 1696-1702.

39. Hoogendijk, W.J., Lips, P., Dik, M.G., Deeg, D.J., Beekman, A.T., Penninx, B.W. Depression is associated with decreased 25-hydroxyvitamin D and increased parathyroid hormone levels in older adults. Arch. Gen. Psychiatry. 2008; 65, 508-512.

40. Stewart, R., Hirani, V. Relationship between vitamin $\mathrm{D}$ levels and depressive symptoms in older residents from a national survey population. Psychosom. Med. 2010; 72, 608-612.

41. Milaneschi, Y., Shardell, M., Corsi, A.M., et al. Serum 25-hydroxyvitamin D and depressive symptoms in older women and men. J. Clin. Endocrinol. Metab.2010.

42. Bertone-Johnson, E.R., Powers, S.I., et al. Vitamin D intake from foods and supplements and depressive symptoms in a diverse population of older women. Am. J. Clin. Nutr. 2011; 94, 1104-1112.

43. Ross AC, Manson JE, Abrams SA et al. The 2011 report on dietary reference intakes for Calium and Vitamin D from the Institute of medicine: what clinicans need to know? J Clin Endocrinol Metab.2011; 96:53-58

44. Brazier M, Grados F, Kamel S, et al. Clinical and laboratory safety of one year's use of a combination calcium + vitamin $\mathrm{D}$ tablet in abmulatory elderly women with vitamin D insufficiency: results of a multicenter, randomized, double-blind, placebo-controlled study. Clin Ther. 2005; 27:1885-1893.

45. Trivedi DP, Doll R, Khaw KT. Effect of four monthly oral vitamin D3 (cholecalciferol) supplementation on fractures and mortality in men and women living in the community: randomized double blind controlled trial. BMJ.2003; 326:469 
46. Mosekilde, L., Hermann, A.P., BeckNielsen, H., Charles, P., Nielsen, S.P. \& Sorensen, O.H. The Danish Osteoporosis Prevention Study (DOPS): project design and inclusion of 2016 normal perimenopausal women. Maturitas.1999, 31, 207-209 